\title{
Practical Training in Innovative Engineering Activity
}

\author{
Nikolay Ivanovich Naumkin*, Gennady Ivanovich Shabanov, Natalia Nikolayevna Shekshaeva, \\ Vladimir Fedorovich Kupryashkin and Elena Petrovna Grocheva
}

N.P. Ogarev Mordovia State University, Saransk, The Republic of Mordovia, Russia; naumn@yandex.ru

\begin{abstract}
The paper is concerned with the content of practical training in innovative engineering activity carried out in summer science student schools which focus on teaching how to obtain tangible innovative products. Items of digital production (printing out on a 3D printer) serve as examples of tangible innovative products and application documents for patents, i.e. intangible innovative products. The training is organized in the form of a business game "Firm-2", comprising the following stages: 1) team building, assignment of roles; 2) establishment of a company, the choice of company's activities and brand name; 3) formulation of the problem to be solved; 4) finding technical solutions; 5) development of a 3D model of the workpiece; 6) development of the product using a 3D printer; 7) submission of applications for RIA; 8) defense of the project. The paper experimentally proves the enhancement of training efficiency by $16 \%$.
\end{abstract}

Keywords: Competence, Competency, Elements of Competency, Innovative Engineering Activity, Intangible Innovative Product, Learning Innovation, Methods of Teaching, National Research University, Summer Science Schools, Tangible Innovative Product, Training

\section{Introduction}

The recently declared modernization of Russia's industry and its new stage of industrialization based on an innovative approach are impossible without the development and improvement of engineering education as the latter sets the goal of raising the level of students' training, prepared to embrace Innovative Engineering Activity (IEA). To enhance efficiency of such training, the Russia's government awarded to a group of higher education institutions a specific status - National Research Universities (NRU). It enables to strengthen and integrate a university's scientific, technical and educational potential and to turn it towards inventing a comprehensive strategy for the country's innovative development. On the one hand, such universities offer new and unique opportunities for effective learning, on the other - set new advanced requirements to university's students, teaching staff and researchers ${ }^{1-4}$.

The above IEA includes certain stages of the full innovation cycle: the analysis of the current technical level, the synthesis of a new technical solution, development, production of new equipment and technologies available as commercial output, presented by Intangible Innovative Products (IIP) in the form of documents of title for intellectual activity results, scientific and technological documentation, as well as Tangible Innovative Products (TIP) in the form of goods, works and services ensuring economic, social or other impacts and thus being competitive ${ }^{5-11}$. Therefore, preparing students for the IEA should be based on their involvement, during training, in all these stages of the innovation cycle. This paper is concerned with extending bachelor training efficiency in IEA at research-intensive universities based on hands-on training i.e. obtaining TIP, in the framework of the regional summer science schools for students, postgraduates and young scholars.

\section{Literature Review}

In our earlier papers ${ }^{2,3}$ we explained that for the practical training in innovative activity it is advisable to teach how to obtain tangible innovative products through

\footnotetext{
${ }^{*}$ Author for correspondence
} 
summer science schools. Such schools have been held by the chair of mechanical design of mechanisms and machines at Ogarev Mordovia State University since $2001^{3}$ and the accumulated experience allows us to conclude the following: 1) summer schools studies enable to fully develop competence in innovative engineering activity because this form of active study combines active recreation and intensive learning; 2 ) creation of academic environment for learners in summer time is efficient not only for students but also for a region in general as young people is the most open and proactive part of society and to use their potential in solving topical issues quite often allows to work out new ideas and mechanisms for putting them into practice; 3) choice of regional summer science schools for students, postgraduates and young scholars as a second (practical) stage of broadening IEA's competences ensures the enhancement of efficiency of students' training in IEA; 4) enhancement of efficiency of summer schools is ensured by the use of teaching methodology based on integrated pedagogical technology where cooperative pedagogy is underlying ${ }^{7}$.

\section{Methodology}

As stated earlier and proved by the studies of E. P. Groshevaya, N. I. Naumkin and other authors ${ }^{12-15}$, innovative engineering activity is mainly carried out in the framework of the innovation cycle. Therefore, the most successfully development of competences through summer school will be performed if we organize the learning process in a way when students go through all stages of practical work being engaged in IEA modeling with further obtaining an innovative product in the form of industrial sample (prototype). In our opinion, such training can be conducted by using digital technologies for the fabrication of innovative products ${ }^{16-21}$, which began to develop rapidly approximately since 80 -ies of the last century and are being widely used worldwide. Their main difference from previous technologies pertaining to creation of three-dimensional objects is that they are not based on the removal of material (lathe turning, milling, EDM etc.) or change of a rough workpiece shape (such as forging, stamping, pressing), but on the gradual growth (adding) of material or change of the phase state of matter in a given area of space.

Today these technologies are known as: SFF (Solid Freeform Fabrication), FFFF (Fast Free Form Fabrication) or CARP (Computer Aided Rapid Prototyping); (STL Stereolithography); (SGC - Solid Ground Curing); (FDM
- Fused Deposition Modeling); (BPM - Ballistic Particle Manufacturing); (SLS - Selective Laser Sintering); (LOM Laminated Object Modeling); (MJM Multi Jet Modeling); immersion centers or virtual reality systems. ${ }^{9}$. All these technologies require the presence of a three-dimensional computer model of a workpiece being fabricated and the process of obtaining products has received a generic name - rapid prototyping.

Considering the great possibilities of the above technologies Institute of Mechanics and Power Engineering of N. P. Ogarev Mordovia State University, in compliance with the development program of a national research university has created, on the basis of the centre for digital production, the division of rapid prototyping ${ }^{3}$, where one of the above-mentioned technological schemes is used: 3D model - 3D printing - prototype - copying.

Of all available digital production facilities for summer science school we have chosen a $3 \mathrm{D}$ printer BFB 3000 as an innovative technology teaching aid which represents a unique, modern model from the Bits from Bytes Company. With its performance and functionality similar to full-printers, it has the advantage of a light weight and compact dimensions and can therefore be installed in a regular office, any room or premises, not mentioning the off-site nature of a science school, and is operable 24 hours a day. The device has a simple and easyto-understand interface, in some cases; it can be used without being connected to the computer, downloading all the necessary data via removable media. The device allows you to model objects with cross dimensions of up to $30 \mathrm{~cm}$ and at a speed of up to $15 \mathrm{~mm}^{3} / \mathrm{sec}$. The capability of color printing is an important feature of this model. Due to this, it allows you to get the most complete picture of the design characteristics of the facility and to pay due attention to the experiments in this area. The models obtained in this printer are characterized by the required quality, reasonable accuracy and the highest level of detail, given quality consumable materials are used. It is using this $3 \mathrm{D}$ printer that enabled all summer school learners to prepare models of Tangible Innovative Products (TIP)

\section{Results}

Teaching IEA in the above schools, as noticed in our early papers ${ }^{2,3}$, is carried out in the form of a business game "Firm-2" (Figure 1), an upgrade of the business game "Firm-1", containing the 2nd practical stage with additional teaching aids (3D printer, collection of 
scripts for creative competitions and sporting events) and advanced content (creation of TIP), which allows simulating all stages of IEA innovation cycle, engaging students. Figure 1 shows that in comparison with the previous business game "Firm-1", this game is carried out in several stages: 1) team building; 2) establishment of a company, the choice of company's activities and brand name; 3 ) formulation of the problem to be solved; 4) finding technical solution; 5) development of a $3 \mathrm{D}$ workpiece model; 6) development of the product using a 3D printer; 7) submitting applications for RIA; 8) defense of the project.

A group of students (6-7 persons) independently turns into a firm (company), which operates throughout their studies and includes an intermediate and final assessment, but, in contrast to the traditional activity, the teamwork is carried out not only during studies but also during all creative competitions, sporting and other events. Members of the group choose a leader who assigns roles (director, technical director, chief designer, patent engineer, economist, and marketing manager). He/She then holds a meeting devoted to the choice of activities of the newly-formed "company», development of a «brand name» as the object of intellectual property. For the fulfillment of the main stage of the game (obtaining intangible and tangible IP) the team independently defines a problem in the chosen field of activity, formulates a clear objective to be gained to solve a problem and synthesizes Technical Solutions (TS).

Of all available TS the team has to choose the most eligible one for registration, submits the documentation for a RF patent to protect the obtained solution. Next assignment for the 'firm' is to develop a trademark or service mark for the anticipated release of the product (product, service) and to submit applicant materials for registration and issuance of a trademark certificate. Along with the above assignments each team received another task: to develop a 3D model of one of the main work pieces based on the obtained technical solutions, print it out using a 3D printer and demonstrate it when the project is being defended. This ensures the efficient development of the students' ability to synthesize and to design the product, to use knowledge of CAD and information storage, facilitates the development of creative imaging. ${ }^{3}$. Obtaining the finished product, in turn, encourages the ability to commercialize the solution and to possess production technologies, the ability to follow up on to the decision. All this altogether forms a positive motivation in obtaining an IP. Defense of the project, as well as in the game "Firm-1" is carried out in the form of slide presentation prepared by each 'firm' in front of the group of experts and members of other teams.

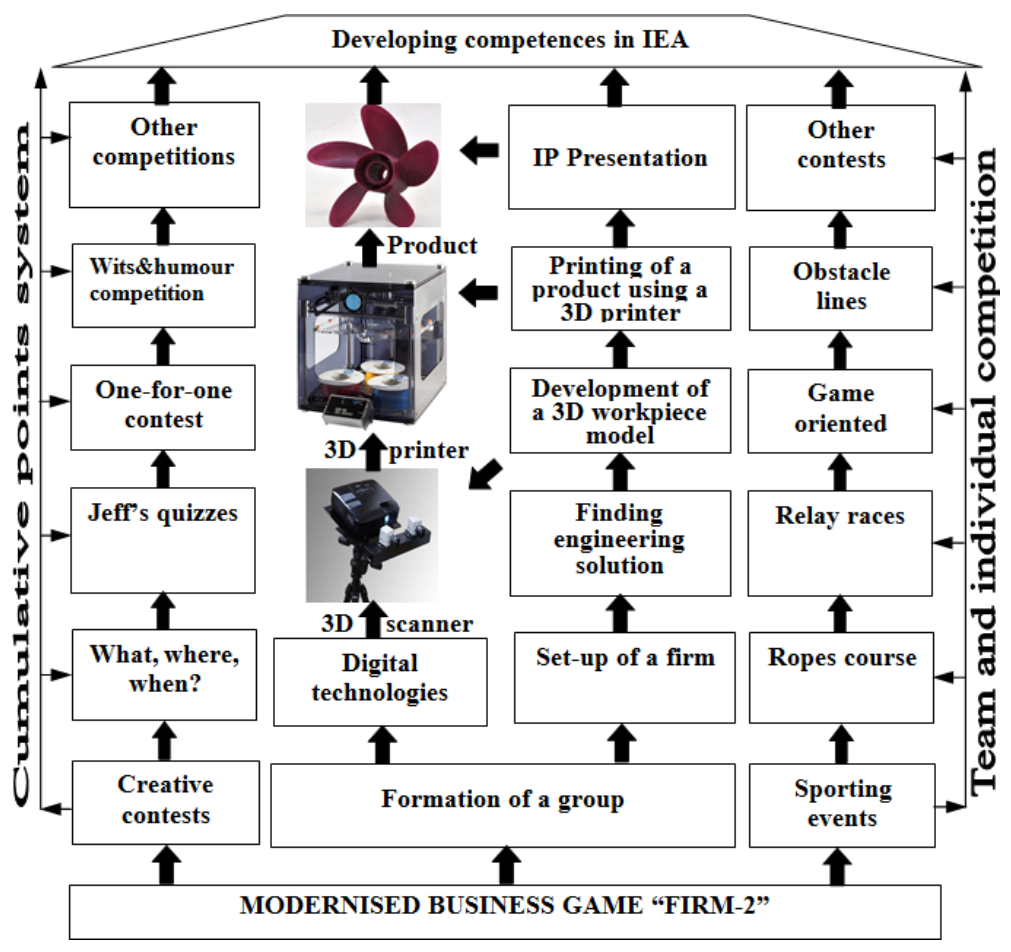

Figure 1. Implementation diagram of a business game "Firm-2". 
Each participant has the floor in accordance with his/her position, presenting the RIA, developed and fabricated IP (brand name, trademark or service mark, invention, utility model, industrial prototype), and describing its potential application and the expected effect.

Attendees can ask questions and participate in the discussions. Experts take the final decision based on the results of the defense (preparation of patent application, publication of scientific papers, and recommendation for implementation). Additional participation of summer school learners in competitions and sporting activities was aimed at team building when solving problems, at identifying the true leaders, creating the ability to act and make decisions quickly and be responsible for them afterwards. Moreover, creative competitions contribute to the development of creative students' potential which is the essential element of the IEA.

Throughout the game a cumulative system of points (individual and team) was used when each team member was responsible for his/her actions before the team and for the team as a whole, under conditions of the need for mandatory decision-making in extreme situations (stress, lack of time, responsibility and so on). To demonstrate the amount of accumulated points there was a wall-mount record of learners' and teams' activity to be constantly filled in. It was also one of the main motives of active, responsible and effective work. Therefore, theoretical and practical training in Educational Innovative Engineering Activity (EIEA) simulates all stages of the innovation cycle, providing effective preparedness to carry out IEA.

\section{Discussion}

To assess the efficiency of development of competency in innovative engineering activity among school learners a pedagogical experiment, based on the earlier developed methodology, was held ${ }^{22,23}$. The school learners were tested before and after training. The experiment sought to define the level at which learners were able to use their (low - 1, medium - 2, high - 3) competencies which determined their overall competency in IEA. Radar charts were prepared (Figure 2), based on the results of testing which implies that before the training, the learners' competences in general were at a medium level equal to 2.5 having an uneven character, after studies this level has significantly grown in average to the value 2.9 , and what is most significant the chart began to be more uniform in nature. This allows us to make an important conclusion that, despite the brief character of the event, it is quite effective for the preparation to IEA and harmonizes the levels of mastery for the whole range of competencies.

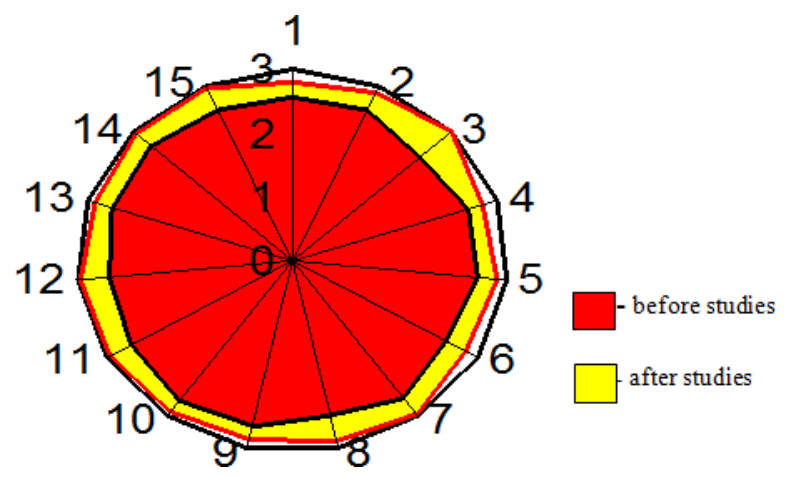

Figure 2. Chart of average index change in IEA competency.

Apart from the qualitative results of the pedagogical experiment, the effectiveness of summer schools is proved by quantitative indicators: 1) learners participation resulted in over 50 publications, including peer-reviewed publications; 2) 10 patents for utility models and inventions were received and proposals for technical improvement were made; 3) from 2012 to 2014, three students of N. P. Ogarev Mordovia State University became the laureates of the Presidential support program for talented young people; 4) a grant totaling 2 million rubles for the competitive selection of one and two-year projects pertaining to implementation and development of programs encouraging student design bureaus and similar public associations of students in the framework of the clause 2.4 under the Federal earmarked program "Science and Pedagogical Staff of Innovation Russia" was won; 5) annual victories of students in international and nation-wide student academic Olympics in Agro engineering; 6) 4 students won presidential and governmental scholarships.

\section{Conclusion}

In view of the above it can be concluded that high efficiency of summer schools is achieved by modeling all stages of innovation, a proper organization of its operation mode, an intelligent combination of studies and recreation, and a rational distribution of academic timetable aimed at fruitful creative work. 


\section{References}

1. Zhurakovsky VM. National Research Universities as Centers of Innovation Activity. Higher Technical Education as a Tool for Innovation Development: program and proceedings of Scientific School with international participation. Kazan: KNRTU Press; 2011[in Russian].

2. Naumkin NI, Kupryashkin VF, Grosheva EP, Shekshaeva NN, Panyushkina EN. Integrated Technology of Competence Staged Formation in Innovation through Pedagogy of Cooperation. World Applied Sciences Journal. 2013; 27(7):935-8. Available from: http://www.idosi.org/wasj/ wasj27(7)13/21.pdf

3. Naumkin NI, Shekshaeva NN, Grosheva EP, Kupryashkin VF. Training the Students of National Research Universities for Innovative Engineering Activities Based on Integration of Theoretical and Practical Teaching of this Activity. Saransk: Mordovia State University Press; 2014 [in Russian].

4. Pokholkov YP, Agranovich BL. Mission of Innovative (Entrepreneurial) University. Engineering education. 2004; 2:6-11. [in Russian].

5. Agranovich BL, Pokholkov Yu P, Chuchalin AI, Soloviev MA. Innovative engineering education: content and technologies. Innovative University and Innovative Education: Models, Experiences and Perspectives. Proceedings of International Symposium: Moscow. 2003. p. 9-10 [in Russian].

6. Agranovich BL, Chuchalin AI, Soloviev MA. Innovative Engineering Education. Engineering Education. 2003; 1:11-4[in Russian].

7. Gunin VN, Barancheev VP, Ustinov VA, Lyapina SY. Innovation Management: 17-modular program for managers Management of organization. Module 7. Moscow: INFRA; 1999 [in Russian].

8. Ermasov SV, Ermasova NB. Innovation Management. Moscow: Vysshee Obrazovanie; 2007 [in Russian].

9. Marchenko EV. Innovations in Conditions of Reforms. Moscow: Nauchnaya Perspektiva Fund; 1998 [in Russian].

10. Kukin AV, Salnikov VA. Innovation activities in the Engineering Education. Engineering Education. 2004; 2:98-103
[inRussian].

11. Rogers EM. Diffusion of Innovation. 3d ed. New York: Free Press; 1983.

12. Amonashvilish A. Grounds for Pedagogy of Cooperation. Moscow: Pedagogika; 1989.

13. Anisimov NM. Technology of Training Inventive and Innovative Activities. Moscow: Prometheus; 1997 [in Russian].

14. Carroll JB. A Model of School Learning. TeachersCollegeRecord. 1963; 64:723-33.

15. Klarin MV. Pedagogical Technologies in Educational Process. Analysis of foreign experience. Moscow: Znanie; 1989 [in Russian].

16. Gohshtand AD. Innovative activity as a special kind of economic activity. Patentsandlicenses. 2007; 1:56-62. [in Russian].

17. Dixon JR. Design Engineering: Inventiveness Analysis and Decision Making. (Transl. form English) Moscow: Mir; 1969 [in Russian].

18. Zinov VG. Intellectual Property Management. Moscow: Delo; 2003 [in Russian].

19. Kokurin DI, Shepelev VM. Innovations in Russia: Institutional Analysis (the problem of ownership, market and tax incentives). Moscow: INIC Rospatenta; 2002 [in Russian].

20. MES RF. National innovation system and state innovation policy of the Russian Federation. Baseline Report for the review of the OECD. 2009; Available from: http://rosmu.ru/ activity/attach/opinions/114/doklad.pdf [in Russian].

21. Skoblyakova I. Innovative Development of Russia's Economy. Interaction of the intellectual property market. Intellectual Property. Industrial property. 2007; 5:9-18 [in Russian].

22. Foray D, Lundvall B. The knowledge-based economy: from the economics of knowledge to the learning economy. Employment and Growth in the Knowledge-based Economy. OECD. Paris; 1996

23. Chernilevsky DV, Filatov OK. Technology of Training in Higher School. Moscow: Ekspeditor; 1996 [in Russian]. 